\title{
O caso Paco: um exemplo de neodesencadeamento
}

\author{
The Paco case: an example of neo-onset
}

El caso Paco: un ejemplo de neodesencadenamiento

\author{
Elizabete Siqueira* \\ Edilene Queiroz ${ }^{* *}$
}

\begin{abstract}
Resumo
Este trabalho é produto de uma investigação empreendida sobre $O$ estatuto contemporâneo das identificaçôes em sujeitos com marcas e alteraçôes corporais, no Programa de Pós-graduação em Psicologia Clínica da Universidade Católica de Pernambuco. Foram estudados os depoimentos coletados em outra pesquisa realizada no âmbito da Antropologia pela pesquisadora Fabiana Maria Gama Pereira, intitulada Tatuagens, piercings e outras marcas corporais: aproximaçôes interetnográficas entre Recife e Madri. A metodologia utilizada foi a meta-análise. Os relatos de quatro sujeitos que submeteram seus corpos a alterações corporais foram analisados com base nos pressupostos da psicanálise. Eles foram divididos em dois grupos: o primeiro, composto por três sujeitos que marcam seus corpos para o Outro em busca de reconhecimento; e o outro, por um sujeito que ancora seu ser em suas modificaçôes corporais e tem uma modalidade identificatória peculiar a uma insígnia de gozo. Nosso objetivo é demonstrar que o caso do sujeito do segundo grupo representa um exemplo paradigmático de um neodesencadeamento psicótico.
\end{abstract}

Palavras-chave: marcas corporais; insígnia; gozo; neodesencadeamento psicótico.

\begin{abstract}
This work results from an investigation on the Contemporary Statute of the Identification Devices in Subjects with Body Marks and Changes in the Program of Post-Graduation in Clinical Psychology of Pernambuco State's Catholic University. Testimonies from another research (Tattoos,
\end{abstract}

\footnotetext{
Doutoranda e mestra em Psicologia Clínica pela Universidade Católica de Pernambuco (Unicap), psicanalista, membro da Escola Brasileira de Psicanálise e da AMP. Endereço: Rua Domício Rangel, 70, apto. 1001 - Boa Viagem, CEP: 51011 570. Recife-PE. E-mail: betesiqueira1@gmail.com.

** Pós-doutora (Laboratoire de Psychopatholie Clinique, Université de Aix-Marseille I), doutora em Psicologia Clínica (PUC SP), professora titular e membro do Programa de Pós-graduação em Psicologia Clínica e Coordenadora do Laboratório de Psicopatologia Fundamental e Psicanálise (Unicap), psicanalista, membro da Associação Universitária de Pesquisa em Psicopatologia Fundamental, pesquisadora P- 2 do CNPq. Endereço: Praça de Casa Forte, 354, AP. 1402 - Casa Forte, CEP: 52061-420. Recife-PE. Tel.: (81) 3268-5482. E-mail: equeiroz@unicap.br.
} 
piercings and other body marks: inter-ethnographic similarities between Recife and Madrid) were studied in the scope of Anthropology by researcher Fabiana Maria Gama Pereira. The methodology employed was meta-analysis. Interviews with four subjects who underwent body changes were analyzed according to the principles of psychoanalysis. They were divided into two groups, the first made up of three subjects who mark their bodies for the Other in search of recognition and the second consisting of one subject who anchors his being in his body changes and shows an identifying modality similar to a pleasure badge. Our aim is to show that this particular case represents a paradigm for a psychotic neo-onset.

Keywords: body marks; badge; pleasure; psychotic neo-onset.

\section{Resumen}

Este trabajo es el producto de una investigación realizada sobre Lasituación contemporánea de las identificaciones en sujetos con modificaciones corporales en el programa del Posgrado en Psicología Clínica de la Universidad Católica de Pernambuco. Fueron estudiados los datos colectados en otra pesquisa del campo de la etnología por la pesquisadora Fabiana Maria da Gama Pereira, titulada Tatuajes, piercings y otras alteraciones corporales: similitudes interetnográficas entre Recife y Madrid. El meta-análisis fue la metodología utilizada. Lo relatado por los cuatro sujetos fue analizado desde la teoría psicoanalítica. Los sujetos fueron repartidos en dos grupos: el primero fue compuesto por tres sujetos que modifican sus cuerpos para el otro en búsqueda de su reconocimiento; y el otro por un sujeto que ancla su ser en sus modificaciones y posee una modalidad identificatoria peculiar a una insignia del goce. Nuestro propósito es demostrar que su caso es un ejemplo típico del neodesencadenamiento psicótico.

Palabras-clave: alteraciones corporales; insignia; goce; neodesencadenamiento psicótico.

\section{Apresentação}

0 estudo que ora apresentamos é produto de uma investigação empreendida sobre $O$ estatuto contemporâneo das identificaçôes em sujeitos com marcas e alteraçôes corporais, realizada nos anos de 2008 e 2009, no Programa de Pós-graduação em Psicologia Clínica da Universidade Católica de Pernambuco. O objetivo principal foi aprofundar o conceito de identificação e investigar sua dinâmica em sujeitos que se submetem a alteraçôes corporais do tipo piercings, tatuagens, escarificações, suspensões e modificações 
corporais, analisando os depoimentos coletados numa outra pesquisa, mas de caráter antropológico, realizada pela pesquisadora Fabiana Maria Gama Pereira em 2007, intitulada Tatuagens, piercings e outras marcas corporais: aproximaçôes interetnográficas entre Recife e Madri.

O interesse por esse tema nasceu do desejo de articular dois tópicos que atualmente não cessam de convocar nossa atenção: por um lado, o corpo e as vicissitudes contemporâneas da identificação em tempos de fragilidade de referências simbólicas consistentes e, por outro, a mobilização causada pela escuta e leitura da pesquisa de Pereira, a qual mobilizou em nós a indagação, originando a nossa pesquisa, de como estaria estruturado o mecanismo da identificação nos sujeitos por ela pesquisados. Por que tomar o corpo como tela de inscrição de modalidades de gozo, algumas vezes mortíferas, e que relação teria isso com uma possível fragilidade das identificaçóes simbólicas e suas consequências para o sujeito?

Realizamos uma meta-análise, mais precisamente uma análise clínica dos dados de fala de quatro sujeitos que submeteram seus corpos a tatuagens e alteraçôes corporais, com base nos pressupostos da Psicanálise. Os sujeitos foram separados em dois grupos, conforme eles estão regidos por lógicas distintas: aqueles organizados pela lógica do ter e aquele que ancora seu ser em suas tatuagens e modificações corporais. Trata-se, neste artigo, portanto, de um sujeito que apresenta a peculiaridade de ancorar seu ser em suas modificaçôes corporais e está identificado a uma insígnia de gozo, além de representar um exemplo paradigmático de um neodesencadeamento da psicose pela via de um gozo desmedido.

\section{A identificação}

A identificação é a mais remota forma de vínculo e está na origem da constituição do sujeito e do laço social. Um processo bem-sucedido de identificação permite, entre outras coisas, em sua vertente social, a compatibilidade necessária para o diálogo humano, uma vez que portador e mediador de uma determinada cultura asseguram sua transmissão e continuidade por meio das gerações (Freud, 1976[1921]).

Entretanto, a civilização atual, regida pela inconsistência do Outro, acabou por questionar alguns significantes clássicos, norteadores do processo de identificação, como o pai, o mestre, o chefe. Atualmente, os sujeitos já não validam a avaliação representativa do Outro e elaboram minuciosamente seus próprios significantes amos. Constroem-nos e 
se atribuem a si mesmos. Nesse contexto, incluem-se as tatuagens e as marcas corporais. Um dos efeitos é um declínio nas identificações verticais, idealmente a um traço significante do Outro, como acontecia quando os significantes mestres eram sólidos. Hoje, eles são múltiplos e líquidos.

Atualmente, observa-se uma expansão identificatória horizontal (Miller, 2005), isso porque, no mundo dos indivíduos, há apenas outros indivíduos, com isso nos referimos a um mundo no qual predomina o gozo do Um, gozo solitário, e identificações com aqueles que compartilham o mesmo traço de gozo. O problemático é que essas identificações imaginárias não formam um conjunto coerente para o sujeito, mas um caos, uma miscelânea de traços pouco organizados os quais ficam à mercê de significantes mestres ditados pela contemporaneidade que mudam de forma tão rápida a ponto de produzir indivíduos desacomodados, atirados ao nomadismo, ao movimento incessante, nessa sociedade multicultural a qual já não tem o Nome-do-pai (Lacan [1955-1956] 1985) como regulador.

Apesar de tudo isso, esse tipo de identificação tem permitido que alguns sujeitos, servindo-se dela, tenham podido encontrar certa estabilidade e um lugar no campo do Outro. Foi isso que se evidenciou nos dados de fala de um dos sujeitos, pertencente ao primeiro grupo estudado na pesquisa acima indicada, a quem ainda nos referimos para sublinhar a diferença estrutural do caso Paco, objeto de estudo deste trabalho. Trata-se de uma jovem adepta da prática de suspensão e portadora de algumas tatuagens, que, no nosso entender, buscava elaborar, por meio delas, conflitos de identidade de matiz edipiano, ou seja, afirmação para separar-se da dependência parental da infância e assegurar um lugar no Outro, como veremos no depoimento a seguir. Ela mantém sua conexão ao Outro, pois o que busca é visibilidade, ser vista e ter um lugar no Outro, mesmo que tenha que pagar com a própria carne. O que faz, faz para o Outro. É apelo, demanda de amor, como testemunha na declaração seguinte, que cito por considerá-la essencial para compreensão da diferenciação que é nosso objetivo destacar:

Dói muito mais do que o piercing. A dor vai aumentando, chega um ponto que você sai do chão e vem aquela dor por todo o seu corpo [...] eu acho incrivel porque você fica sem apoio, parece que tá voando. Eu sempre peço para me balançarem [...] você está pendurado, parece que está com uma asa [...], quanto mais balança vai aliviando até que não sente mais dor, você consegue 
ver a dor abaixo de você, olhando pra você. Depois você passa a ver que a dor não existe. Isso é uma descoberta indescritivel, que a gente não sabe nem descrever. Tudo isto que a gente vê aqui $e ́$ horroroso, mas eu consegui superar a dor, então seu ego [...] você se sente mais do que todo mundo que está aí. Para mim foi muito importante [...] o pessoal, quando eu tava lá em cima, eles gritavam, batiam palma, foi uma emoção! Depois o povo ficou atrás de mim pra saber o que eu tinha sentido. Aonde eu chego, tem gente que me pergunta. Eu acho que eles acharam $o$ máximo e com certeza muitos vão querer fazer porque viram que qualquer pessoa é capaz e notaram que eu fiquei nas nuvens [...] há tu tens que fazer, é bom demais!!!! (Pereira, 2007, p. 137).

Tais sujeitos querem dar a impressão de gozarem de uma liberdade libidinal maior e, no "somos uma máfia" (Pereira, 2007, p. 98), encontramos o signo de uma identificação imaginária aos valores que os unem e de acesso imaginário a um modo de vida desconhecido de todos os outros que não são da paróquia. Buscam, desse modo, garantir uma identidade e lutam para autenticá-la e valorizá-la aos olhos do Outro social.

Com Paco, outro sujeito da acima referida pesquisa, a coisa se passa de outra forma. Ele é um jovem espanhol de 20 anos que se autodenominou o "galo decapitado" (Pereira, 207, p. 150), que nos parece portador de uma organização psíquica diferente da jovem anteriormente indicada. A solução de Paco frente ao real, que logo mais passaremos a descrever (é o que nos interessa) e demonstrar seu esforço para articular e circunscrever uma dificuldade, resolver um problema fundamental que se coloca de forma tal que só faz sentido para ele. Sublinhamos que o que ele tenta dar conta tem para si estatuto de real, no sentido de algo que insiste como fora de sentido e que está retornando sempre ao mesmo lugar. Resumindo, o que nos interessa não é um relato exaustivo do seu romance familiar, por exemplo, mas os termos da cena enigmática na qual ficou aprisionado.

Saiu muito cedo da casa paterna e vem submetendo seu corpo a transformações progressivas e ininterruptas, com fins de controle dos pensamentos. Fala de si por meio de seus diversos signos corporais: piercings, tatuagens, escarificaçóes e implantes. Informa que tudo começou aos 17 anos, quando encontrou Marc, que o iniciou nesse universo, distanciando-o assim do mundo mais perigoso de traficante e usuário de drogas. Observa Paco: "Eu antes não trabalhava. Desde que 
comecei a colocar piercing, me tranquilizei. Antes eu tinha uma vida muito irresponsável, hoje, conheço muita gente" (Pereira, 2007, p. 150).

Diz que, para ele, a escarificação é muito importante, pois significa controle mental, controle da dor e, quando a faz, sente-se muito bem. Esclarece que é uma técnica difícil e que se sente orgulhoso em ser portador das referidas marcas, bem como em dominar a técnica. Insiste no significado de controle da mente que têm para ele:

São intervençôes que dão ao individuo a capacidade de controle da mente e dos pensamentos. Eu conheço quatro ou cinco pessoas que entendem de escarificação, não conheço muito mais, não é que pensem como eu, mas que compreendem. Tu me entendes se eu vou cortar a perna? Não te parece estranho? Todo mundo é assim, ninguém entende, ninguém compreende. Cada coisa que faço, utilizo o interior do cérebro, desenvolvo coisas que as pessoas não desenvolvem: quando tu estudas, desenvolves uma parte da tua cabeça: tem gente que não estuda, não desenvolve, então eu, ao fazer isto, desenvolvo (Pereira, 2007, p. 102).

Considera que teve uma vida muito louca, com drogas, sexo e violência, e que já foi atropelado. Que sempre esteve perdido, fazendo coisas más. Informa sobre sua intenção de tatuar uma morte japonesa, a dama da foice, a típica morte numa adaptação japonesa, para com isso marcar que a morte nos acompanha a vida toda até que um dia nos abate. Conta que, dentro dessa rede de comerciantes, um dos amigos foi morto e que, após esse episódio, passou a se sentir perseguido, tinha a sensação de estar sendo seguido.

Revela que o pai morreu há cinco anos em decorrência de alcoolismo. Ele era agressivo, bebia muito, era muito ausente e, quando estava em casa, batia nele e nos irmãos. Ele tinha uma fazenda e seu último desejo foi ter suas cinzas jogadas em uma árvore que ele mesmo plantara havia 25 anos. Nesse contexto de fala, conta que, após a morte do pai, tatuou essa árvore por trás dos ombros. Chama-lhe a atenção ser uma árvore seca, sem folhas, que o representa, pois, à semelhança da árvore, não pode dar mais frutos, pois está sem vida, mas que uma árvore nunca morre: as árvores representam a vida eterna.

Seu nickname na internet é "El gallo decapitado siguió corriendo alrrededor de la horca haciendo un círculo de sangre fresca" (O galo decapitado seguiu correndo ao redor da forca, fazendo um círculo de sangue fresco). O significado que ele dá a desse nome é que a forca é um pau colocado com uma corda onde se colocam as pessoas para matá- 
las. Na forca, há um homem morto, com o pescoço quebrado e a cara roxa. Ao redor, há um galo correndo, sem cabeça, e do pescoço sai um jorro de sangue, e, como o galo corre em círculos, em torno da forca, forma um círculo de sangue vermelho em cima da neve branca. Por meio dessa narrativa do que ele diz ser um sonho, recorre às lembranças de infância das matanças de galos e perus que eram realizadas na fazenda do seu pai e em que, em algumas ocasióes, era ele, Paco, quem segurava os animais para serem degolados. Confessa que não consegue apagar da sua memória a cena em que as aves corriam sem cabeça e jorrava sangue pelo pescoço até caírem mortas no chão e que, certa vez, teve de fazer força para agarrar uma para ser morta.

Conta que, sem entender, passou a sentir, muitas vezes, a necessidade de furar o próprio corpo, sobretudo nos momentos em que se sente ansioso ou frustrado. Quando se separou de L., sentiu vontade de se perfurar o tempo todo. Era um desespero, furou o rosto e os dois mamilos, e, por meio desse ato, buscava controlar a mente.

Revela que, cada vez que se escarifica, ou se coloca um piercing, põe-se à prova, conhece sua mente um pouco melhor e até aonde pode chegar. Percebe que, a cada vez, pode se controlar um pouco mais, isso porque os medos voltam e as descargas diminuem; então sente necessidade de ir um pouco mais além a cada vez. Define-se como uma pessoa completamente louca, que muda a aparência e experimenta novas sensações.

Associa a relação que estabeleceu com seu corpo, de cortá-lo, perfurálo com a doença da família materna.

Eu sou igual a minha mãe. Eu acho que ela é esquizofrênica. Ela via coisas e foi internada. Você sabe, esquizofrenia pode estar na genética. Então, quando eu me corto ou me perfuro, eu também aprendo a controlar minha cabeça (Pereira, 2007, p. 150).

Paco submete-se também, regularmente, a suspensões. Declara que, numa delas, poderia ter ficado pendurado um dia inteiro, de tão bom que foi. Informa que tem feito muitas performances e que é muito bom superar os limites da dor, concentrar-se, controlar o próprio corpo. Ressalta que há pessoas que querem fazer suspensões em bares, mas que ele não gosta disso. Quer fazer para ele e não para ser visto por um público. Para ele, a suspensão é uma experiência e não algo para comércio, completamente diferente da jovem que faz para o Outro, para ser vista e admirada. 


\section{O gozo}

Paco, por conseguinte, não consegue remeter seu mais de gozar para o endereço adequado, ou seja, para as zonas erógenas do corpo, que, como pontos localizados e circunscritos, condensam e processam o gozo do corpo, protegendo-o dessa onda devastadora. Como não consegue o endereçamento devido, há um retorno maciço e generalizado de gozo sobre seu corpo, presença que nos permite deduzir um funcionamento deficitário da metáfora paterna e de uma função paterna tomada como decadente, ridícula, sem peso.

É um exemplo cristalino de como se dá o desencadeamento da pulsão de morte sob novas formas. Seu caso mostra que há gozo e tirania da pulsão ali onde existe satisfação destrutiva. Na busca de uma suplência imaginária do pai decadente que lhe outorgue recursos para regular o gozo do corpo, acaba regido e obedecendo a uma ordem de ferro: "Marcate, mais, mais ainda; ainda mais, indefinidamente", dando partida a um ciclo vicioso sem ponto de parada. O que observamos na ausência do simbólico do pai é a entrada em cena do real do pai que, como pai gozador, não freia os excessos, mas é ele mesmo a figura excessiva que o tem levado ao pior, na forma de mutilar-se a si mesmo.

Essa é, portanto, sua tentativa de autotratamento, busca de uma envoltura psíquica formal, consistente, que the dê acesso a uma representação mental possível de ser tratada pela operação inconsciente do sentido. Paco olhou e participou da cena. Como os galos, ele também era submetido à agressividade do pai. Enredado na cena, não pôde significá-la numa representação mental e aprisionou-se na posição autoerótica, que o levou à construção de uma identidade substituta, fundada sobre a identificação a essa insígnia de gozo, que o tem levado a uma verdadeira alteração da imagem de si.

É bem evidente em Paco que seu objetivo não é estético ou representacional, que o crucial é o próprio processo de tatuar-se, forma extremada de garantir que continua vivo, que não está morto como o "galo decapitado" do seu fantasma inscrito no real do seu corpo, mas que, ao mesmo tempo, reedita a cena pelas insistentes perfurações e escarificações que fazem jorrar sangue. É interessante realçar que a cena dos galos correndo e jorrando sangue indicava que os galos continuavam vivos, mesmo que a morte já tivesse a caminho. Reeditando essa cena, Paco parece mostrar que vive no limite da vida e da morte. O tratamento que dá ao seu corpo permite-nos, portanto, pressupor que o desejo não é 
o operador de base, que o gozo é quem está no comando, aprisionando-o no tratamento mortífero que dá ao seu próprio corpo.

Afirmamos, então, que, em Paco, há déficit de simbolização e de acesso à representação mental, o que permitiria o trabalho do sentido que aplacaria a angústia responsável pelas constantes passagens ao ato, às quais ele mesmo se refere. Arriscamo-nos a afirmar que nele há uma foraclusão bem particular da imagem fálica, por carência de representação paterna. Arriscamo-nos ainda a propor que há este buraco em sua estrutura e que, por meio de suas tatuagens, marcas e cortes, busca fazer suplência a esse vazio central. Diríamos mesmo que ensaia pôr nesse lugar uma modalidade delirante (lato sensu) de castração, castração no real do corpo, uma pseudocastração, pseudometafórica. Paco literalmente carrega o pai nas costas, pela via de sua tatuagem.

Nesse contexto, não se pode deixar de considerar haver um sujeito do gozo e um sujeito do significante, e haver situaçôes em que é visível o agenciamento do sujeito do gozo. Miller (2004), referindo-se ao que ele denomina o "último ensino de Lacan", que data das décadas de 1970-80, relembra-nos que é habitual manejarmos com a ideia de descontinuidade entre neurose e psicose, com a ideia de certeza diagnóstica, mas que já se provou que pode haver continuidade, posto que a verdade das coisas humanas é a curva de Gauss. Pois bem, somente a partir de uma concepção como essa se pode ler em uma continuidade o que já não se chamam classes, mas modos de gozo. Há, portanto, nesse momento do ensino de Lacan acima referido, uma clínica orientada pela questão do real e do aparelhamento do gozo.

É uma clínica mais além da clínica estrutural, que distingue as estruturas em função da presença ou ausência do Nome do pai. Esse novo modo de ver as coisas permite um avanço magistral no que diz respeito à noção de desencadeamento, que, a partir daí, pode ser visto como

O tempo zero de um processo evolutivo no transcurso do qual se coloca a questão das acomodações e das suplências possíveis. É a conclusão na qual se conclui uma história que nem sempre pode ser descrita como "um céu calmo" onde irromperia o raio (Miller, 2004, p. 19).

Graças a essas novas ferramentas, tornou-se mais fácil, por exemplo, compreender e acompanhar algo como os novos sintomas que são diretamente ligados às mudanças do Outro e que apresentam formas 
clínicas mais ou menos bizarras, como a de Paco, buscando detectar o que mantém minimamente juntos os registros do Real, do Simbólico e do Imaginário. Dessa forma, pode-se mais ou menos localizar o momento em que o sujeito se desengancha do Outro, e os momentos seguintes reproduzirão esse padrão. Em Paco, tudo indica que foi no momento da matança de galos e depois nos seguintes, de separação e nomadismo. É, portanto, uma clínica dos modos atípicos de desencadeamento porque sem eclosão nítida de fenômenos de alteração de linguagem.

\section{O neodesencadeamento}

Consideramos que o tratamento que dá ao seu corpo, tatuando-se e furando-se sem parar é visivelmente de estrutura toxicômana, similar ao uso que se faz de drogas, e parece encobrir dificuldades pertencentes ao campo dos casos raros e de difícil classificação em psicanálise, por não se localizar um desencadeamento típico, mas que, nem por isso, deixa de ser de natureza psicótica. Com o binômio tatuador-tatuado, busca fazer um tampão no vazio subjetivo em momentos de confrontação com vivências, que remontam à infância, de separação, de desamparo, de solidão, de assujeitamento. Entendemos que há algo de delirante (portanto, da ordem do fenômeno elementar) na fixação à certeza de, pela via de suas técnicas de desafio à dor, fazer um controle da mente e dos pensamentos.

Sobre isso, Miller (2004, p. 20) afirma que "a convicção desses sujeitos sobre sua experiência cenestésica de abolição dos limites da realidade sensível só é comparável ao caráter enigmático e angustiante desse gozo". É o momento do neodesencadeamento, em que o sujeito é marcado por fenômenos de magnitude emocional devastadora, produzindo perda de referências corporais e identificatórias. Vale ressaltar que, segundo Miller (2004), o termo "neodesencadeamento" não designa apenas o desencadeamento psicótico, mas nos permite interrogar como o sujeito se desliga do laço social e se liga ao seu gozo.

Há muitos indícios de que, efetivamente, a experiência dos galos decapitados, sangrando e correndo como mortos-vivos, não foi simbolizada. Localizaria, nesse detalhe do "morto-vivo", o ponto enigmático que não recebeu uma resposta convincente e conciliadora do binômio simbólico-imaginário. Momento de vivência apocalíptica, de confronto com um gozo Outro, totalmente enigmático, que o coloca no lugar de objeto em perigo e para a qual não encontra um modo de 
simbolização, em virtude de esgarçamento do tecido simbólico, que, rompido, impede a possibilidade de aparelhamento significante do gozo. É justamente por ser um "morto-vivo" que ele inscreve o pai morto no real do seu corpo, como árvore morta, para que, como árvore, nunca morra e permaneça vivo enquanto ele assim o for. Solução visivelmente bizarra, não enlaçada pelo binômio acima referido e, como tal, impossível de encontrar uma inscrição significante.

Nossa hipótese é de que Paco não pode subjetivar a repetição de gozo à qual está submetido, e que seu desligamento do Outro não é total, mas em diversos pontos da estrutura: na identificação ao galo decapitado, no tráfico e uso de drogas, na compulsão a se cortar, na errância. São quatro traços clínicos em tempos diferentes que sugerem um desligamento escalonado na história desse sujeito.

Refere empobrecimento dos laços sociais e marginalização: abandono da escola, saída precoce do lar, errância, inquietação, vivência marginal nas ruas, tráfico e uso de drogas. "Vida louca" resume o que considera do seu modus vivendi. Podemos dizer então que, de desligamento em desligamento, pouco a pouco, instaura uma modalidade de vida sem pouso. Posto isso, defendemos a tese de uma resposta maníaca, no sentido que lhe dá Soler (2007), de festa maníaca, na qual estão inoperantes a função paterna e o ideal do eu, e tem no não cessar de atacar o corpo a marca de uma falta de simbolização, sinal de que algo se soltou, desligou-se do Outro e enganchou-se com a cifra de gozo e que põe esse sujeito num risco mortal, de perecimento duplo: como sujeito e como ser vivente.

Paco é uma prova viva de que, apesar dos avanços da ciência e da técnica, os sujeitos podem estar cada dia mais doentes, mais carentes, mais desamparados quando localizam no corpo próprio a evacuação de um gozo desmedido, não temperado pela lógica da função paterna que preconiza identificaçôes fundamentais e ideais, de calado suficiente e leme forte, capazes de dar um rumo à navegação cotidiana pelos bravios mares da vida. Embora a solução de Paco seja uma tentativa de tratamento do gozo, não consegue apaziguar a angústia que o oprime e que o lança numa cruzada de fruições patológicas, regidas pela lógica do mais, mais ainda, sempre mais, esgotante e devastador, a qual, em última instância, desregula os ritmos vitais. Nossa conclusão final é que Paco faz uma tentativa malsucedida de estabilização pela marca e que seu caso é um exemplo paradigmático de um neodesencadeamento. 


\section{Referências}

Freud, S. (1976). Além do princípio de prazer. In: Edição standard brasileira das obras psicológicas completas de Sigmund Freud. (Christiano Monteiro Oiticica, trad., Vol. 18 p. 17-85). Rio de Janeiro: Imago. (Texto original publicado em 1920)

Lacan, J. (1985). O seminário: livro 3: as psicoses. Rio de Janeiro: Jorge Zahar.

Lacan, J. (1985). O seminário: livro 20: mais, ainda. Rio de Janeiro: Jorge Zahar.

Miller, J.-A. (1998). Los signos del goce. Buenos Aires: Paidós.

Miller, J-A. et al. (1998). Os casos raros, inclassificáveis da clínica psicanalítica: a conversação de Arcachon. São Paulo: Biblioteca Freudiana.

Miller, J-A. (2004). La psicosis ordinaria. Buenos Aires: Paidós.

Miller, J. A. \& Laurent, Eric (2005). El Otro que no existe y sus comités de ética. Buenos Aires: Paidós.

Pereira, F. (2007). Tatuagens, piercings e outras marcas corporais. Tese de Doutorado, Programa de Pós-graduação em Antropologia, Universidade Federal de Pernambuco, Recife.

Siqueira, E. R. A. (2009). O estatuto contemporâneo das identificaçôes em sujeitos com marcas e alterações corporais. Dissertação de Mestrado, Programa de Pósgraduação em Psicologia Clínica, Universidade Católica de Pernambuco, Recife.

Soler, C. (2007). Estudios sobre la psicosis. Buenos Aires: Manantial. 